\title{
The Application of Current Requirement Test in Large Oil Field Station
}

\author{
Zhou Bing ${ }^{1,2, ~ *, ~ H a n ~ W e n-l i ~}{ }^{1,2}$, Zhang Ying-ying ${ }^{1,2}$, Guo Ji-yin ${ }^{1,2}$, Zhao Yu-fei ${ }^{1,2}$, Zhang Yan-jun ${ }^{1,2}$ \\ ${ }^{1}$ CNPC Research Institute of Engineering Technology, Tianjin, China \\ ${ }^{2}$ CNPC Key Laboratory of Tubular Goods Engineering, Tianjin, China
}

Email address:

zhoub.cpoe@cnpc.com.cn (Zhou Bing)

${ }^{*}$ Corresponding author

\section{To cite this article:}

Zhou Bing, Han Wen-li, Zhang Ying-ying, Guo Ji-yin, Zhao Yu-fei, Zhang Yan-jun. The Application of Current Requirement Test in Large Oil Field Station. Science Journal of Chemistry. Vol. 5, No. 3, 2017, pp. 42-46. doi: 10.11648/j.sjc.20170503.13

Received: May 18, 2017; Accepted: July 4, 2017; Published: August 7, 2017

\begin{abstract}
Up till now, the local cathodic protection renewal of oil \& gas field station can be only designed based on previous experience. Therefore, it may lead to some facilities out of protection and inhomogeneous distribution of potential. What is worse is that it can cause mutual interference with surrounding systems, resulting in the malfunction of the cathodic protection system. Through the current requirement test, the current density for the effective protection of storage tanks and pipelines can be obtained. Besides, the type and distribution of the anode ground bed can also be optimized. Thanks to the above calculation and optimization, the protection efficiency of the cathodic protection system can be significantly improved. In this paper, on-site current requirement test was conducted in a large oil field station. The simulation of the cathodic protection system was conducted in certain area separately so as to confirm the minimum current density value required for the effective cathodic protection and the potential distribution in certain area, all of which would benefit the redesign and renewal of the local cathodic protection system in the reservoir area.
\end{abstract}

Keywords: Large Oil Field Station, Current Requirement Test, Regional Cathodic Protection, Protection Current Density

\section{Introduction}

Cathodic protection (hereinafter referred to as $\mathrm{CP}$ ) system transformation inlarge oil and gas station, due to the buried facilities is not clear, only can reference to past experience design. This offten lead to: insufficient design current, nonuniform potential distribution, part of the facilities under-protection, even the interference with each other $\mathrm{CP}$ These result in the CP system work unnormally. The current requirement test is: Establish the simulated $\mathrm{CP}$ system and protect the underground facilities in the station. Potential distribution and corresponding current demand of underground facilities are detected, after being fully polarization, current drain point and shielding area are analysised. Location and type of the anode ground beds can be optimized based on the test result in the process of design, and corresponding measures are taken to prevent the insufficient protection of current loss or blocking and interference phenomenon, Which can provide practical data support for the design work and improve the success rate and protection effect of CP system. [1-7, 10]

\section{Main Body}

\subsection{Technical Route and the Test Method}

\subsubsection{Technical Route}

Current requirement test was carried out in a large complex station. Due to the large reservoir area, A single CP system was difficult to cover the whole area, So the reservoir is divided into several blocks of experiment, realizing basic coverage.

According to the distribution of buried pipelines and other facilities within the station, the reservoir area is divided into multiple test units (figure 1).

First, the shallow buried anode CP systems were set up. Through current requirement test, Buried pipeline potential distribution, current demand, current block area, effective protection range were determined, and the total current value 
could be calculated.

\subsubsection{Test Method}

The following test methods are used in this article

(1) Surface reference potential test

(2) Near reference potential test

(3) Close spaced potential measurement (CIPS);

(4) Ground potential gradient detection

\subsubsection{Test Procedure}

After the installation of shallow buried anode CP systems, The current requirement test were started.

(1) Test corrosion potential of the buried pipes in each unit.

(2) Open the CP system, adjust the potentiostat output. After CP systems being polarization stability, test protection potentials of the buried pipelines and record the potentiostat output current.

(3) According to the results of the protection potential, the potential distribution, current demand, current erosion area and the protection range of the shielding area can be determined.

(5) Calculate the total current value of the whole reservoir area.

\subsubsection{Build of the Temporary Cathodic Protection System}

(1) Each testing unit contains 8 anode pits with the size of $3 \times 1 \times(3-4) \mathrm{m}^{3}$. The 8 anode pits were divided into two group averagely. The distribution of the anode pits was show in figure 2 .

(2) In every anode pit, a $1.5 \mathrm{~m}$-long high silicon cast iron auxiliary anode was buried, which is shown in figure 3 .

(3) Conform the location of the cathodic terminal point and the zero cathodic terminal point. Link the cathodic and zero cathodic cable and ensure that in every testing unit there are at least two cathodic terminal points. Besides, the linkage of the cathodic protect system and the buried pipe network must be connected.

(4) Choose the location to bury the reference electrode with the depth of 2-2.5 m. The reference electrode was $\mathrm{Cu} / \mathrm{GuSO}_{4}$ permanent reference electrode. Before buried, the reference electrode was immersed in water for $24 \mathrm{~h}$. Then the electrode was put into the pit with water filled. Subsequently, the pit was backfilled. The construction process was displayed in figure 4

(5) Link the anode cable, cathodic cable, reference cable and zero cathodic cable to the constant potential rectifier separately to complete the temporary cathodic protect system with the rated output of $50 \mathrm{~V} / 30 \mathrm{~A}$ as shown in figure 5 .

\subsection{Analysis of the E Test Results}

\subsubsection{Corrosion Potential Test}

Within the reservoir area on pipe, fire control pipe, fire hydrant, grounding, etc of corrosion potential was tested, including 284 test points, The test point distribution is shown in figure 6 . The test range covers the whole area, Corrosion potential in $0.37 \mathrm{~V} \sim 0.59 \mathrm{~V}$ (vs. CSE, hereinafter the same), as shown in figure 7 .

\subsubsection{Protection Potential Test}

Three sets of temporary CP system at the same time is up and stable polarization, test the protection potential, as shown in figure 8 . The output values of 3 constant potential meters are shown in Table 1.

\subsubsection{Minimum Protection Current Density and the Total Current Calculate}

According to the results of current requirement test, the scope of the effective protection of temporary CP system is determined. By calculating the surface area of protected objects within the range, and according to the corresponding output current, the minimum current density to achieve effective protection can be calculated. Finally according to the area of protected objects, calculate the total required protection current.

Refer to the information of buried pipelines and calculation in the reservoir area, the total surface area of buried pipes is $21561 \mathrm{~m}^{2}$, including epoxy coal asphalt anticorrosive layer of buried pipelines $7316 \mathrm{~m}^{2}$, asphalt anticorrosive glass cloth of buried pipelines $14245 \mathrm{~m}^{2}$. In addition, The surface area of lightning protection anti-static grounding bodys is about 116 $\mathrm{m}^{2}$, So regional CP system to protect the total area is about $21677 \mathrm{~m}^{2}$.

In the effectively protected area of current requirement test, the total surface area of buried pipes is $5100 \mathrm{~m}^{2}$, and the anticorrosive layer is asphalt glass cloth.

When the three sets of temporary CP system overall output current is $17.0 \mathrm{~A}$, the buried pipes and grounding within the area mentioned above all can achieve effective protection. It is concluded that the area protection current density value of $3.33 \mathrm{~mA} / \mathrm{m}^{2}$ through calculation.

Assuming the condition of grounding and buried pipeline coatings in other effective protection area is roughly same, Using direct extrapolation by the test result, In buried pipeline surface area protected area about $5100 \mathrm{~m}^{2}$ of effective domestic demand, current value is $17.0 \mathrm{~A}$, the buried pipeline surface area of $21677 \mathrm{~m}^{2}$ of the reservoir area must be about 72.26 A current value.

According to $\mathrm{CP}$ system design specification and refer to the current requirement test results, considering that the calculated value also takes into the grounding bodys, Asphalt anticorrosive glass cloth of buried pipelines needed for real protection current density value should be less than the calculated value. Therefore, design protection current density are: epoxy coal asphalt anticorrosive layer of buried pipelines $2.5 \mathrm{~m} \mathrm{~A} / \mathrm{m}^{2}$, asphalt anticorrosive glass cloth of buried pipelines $3.5 \mathrm{~m} \mathrm{~A} / \mathrm{m}^{2}$ [8-9], lightning protection anti-static grounding bodys $60 \mathrm{~mA} / \mathrm{m}^{2}$. The design protection current is shown in table 2.

Through calculation, the total CP system design current value of whole reservoir area should be about $68.18 \mathrm{~A}$, with the test value by $5.6 \%$. Considering the part of the current leakage areas, If the calculated current value is increased by $10 \%$, the total CP system design current value should be 75.0 A. The anode ground bed of reservoir area $\mathrm{CP}$ system is recommended to use shallow ground bed, each group of the 
ground bed distance is between 10 15 m.

\subsubsection{Elimination of the Ground Bed Potential Influence Test}

When CP system is running, the electric potential of buried pipeline, in addition to including the IR drop between soil, the anode ground bed potential will also influence the result of the test. The potential gradient method is adopted to test the influence degree of the ground bed potential.4 potential gradient test points are choosen in the reservoir area, including near and far ground bed point. Test points are shown in figure 9 , test results are shown in table 3 .

Test results show that potential gradient near the ground bed is bigger, direction 4 test point which far away from the ground bed is minimal. Soil potential gradient near ground bed is about $9.8 \mathrm{mV} / \mathrm{m} \sim 16.0 \mathrm{mV} / \mathrm{m}$, which produces little influence on the result of the electric potential test.

\subsubsection{Buried Parallel Pipeline Protection Test}

There are a lot of buried pipelines laid in parallel in the reservoir area. Evaluate the protection efficacy of the parallel pipeline by using close analogy method and testing pipeline potential.

Two test points are selected in the reservoir area, which contains three parallel pipelines. When shallow anode ground bed temporary $\mathrm{CP}$ system is running, The protection potential of first test point three parallel pipelines, in turn, is-1.10 V, $-0.98 \mathrm{~V},-1.07 \mathrm{~V}$, The protection potential of second test point three parallel pipelines is $-1.09 \mathrm{~V},-1.04 \mathrm{~V},-1.11 \mathrm{~V}$ in turns. Because both side of two tests has been buried anode, potential moved to negative on both sides and positive in the middle. The potential difference between parallel pipelines is about $20 \mathrm{mV} \sim 70 \mathrm{mV}$.

From the point of test results, there is a potential difference between the parallel pipelines in the range of shallow anode protection.

\subsubsection{Current Requirement Test Summary}

More than once current requirement tests were done in the the reservoir, The summary and analysis are as follows:

(1) The potential gradient is larger, and the single group anode is less protected by using shallow buried bed.

(2) The grounding is easily lost to the CP current.

(3) Two current shielding areas are identified through the test, where the appropriate addition of current is considered in cathodic protection system design.

(4) The distribution of protection potential of the buried network in different output current are determined. The current density and total protection current value of the buried pipelineare calculated.

\section{Details}

\subsection{Figure}

The figures should be clear and they should be numbered as Figure 1, Figure 2, Figure 3, Figure 4 etc. There should be annotations behind each figure as following:

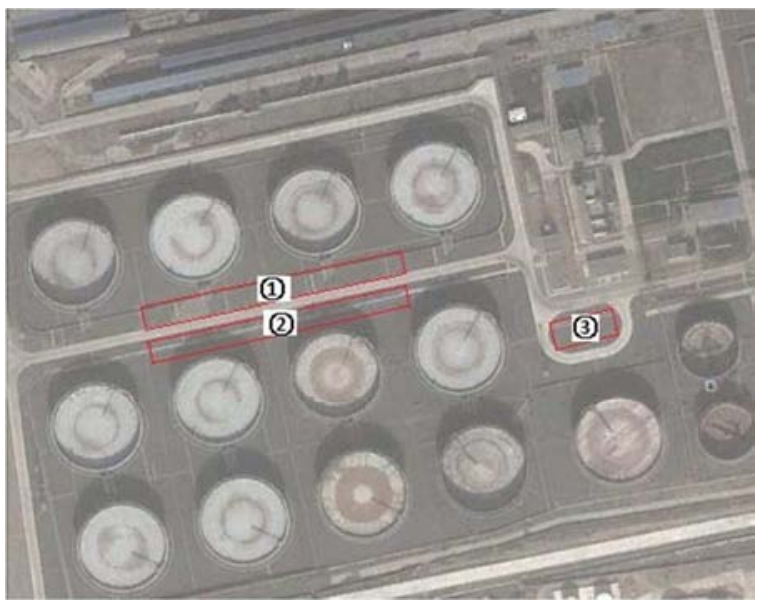

Figure 1. The test unit distribution diagram.

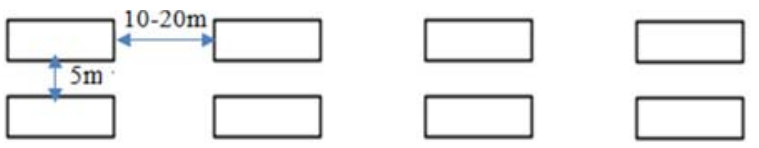

Figure 2. The distribution of the anode pits in each testing unit.

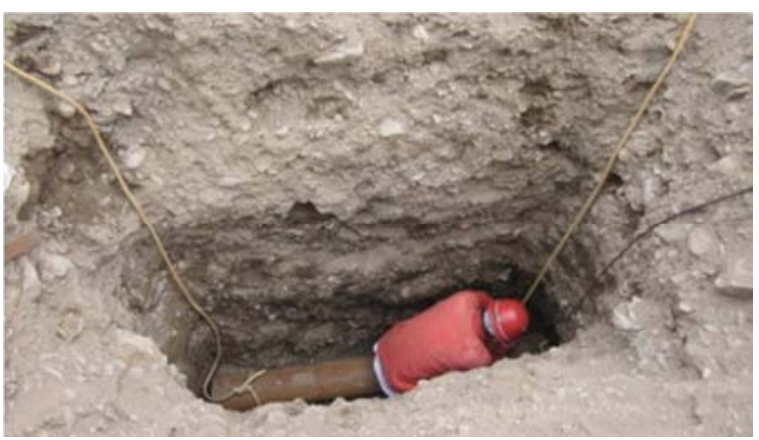

Figure 3. The high silicon cast iron auxiliary anode in the anode pit.
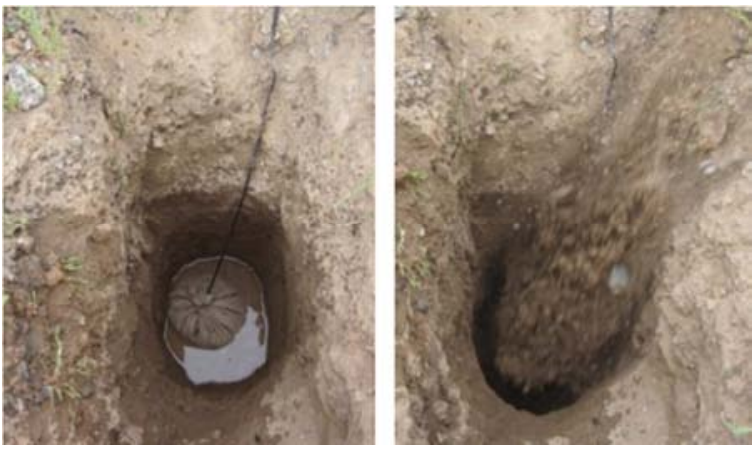

Figure 4. The construction process of burying the reference electrode.

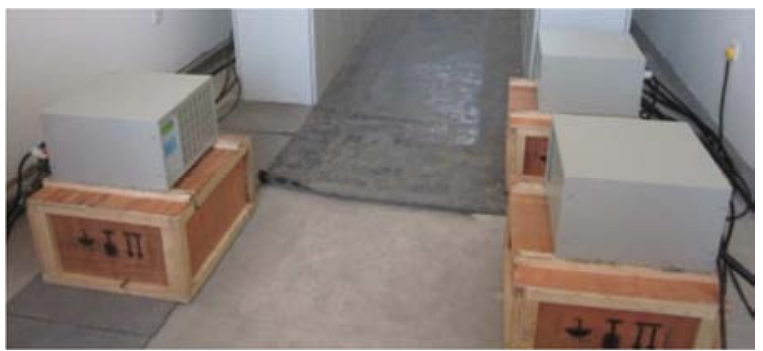

Figure 5. The constant potential rectifier of the temporary cathodic protect system. 

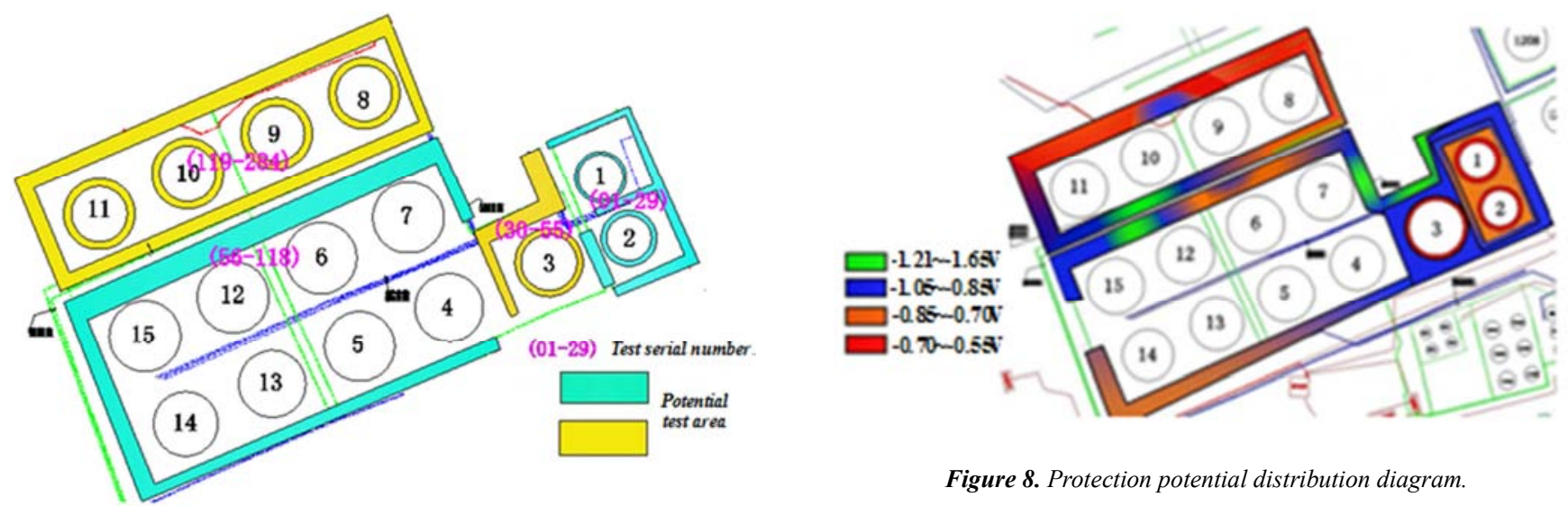

Figure 8. Protection potential distribution diagram.

Figure 6. Potential test point distribution.

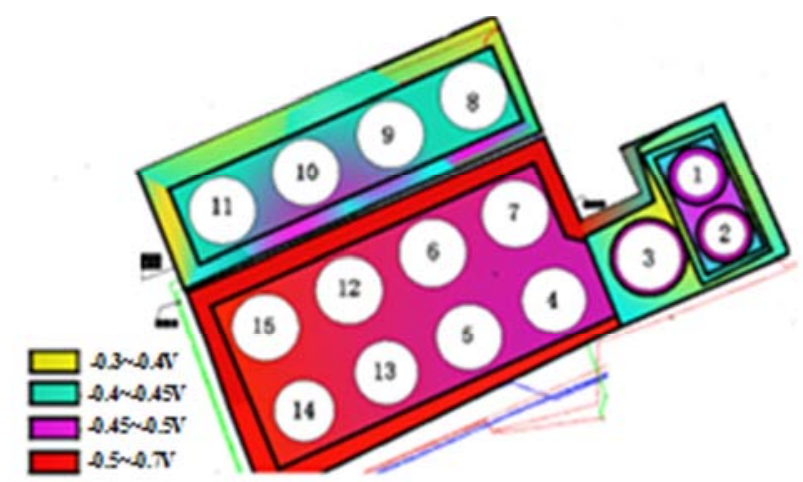

Figure 7. Corrosion potential distribution diagram.

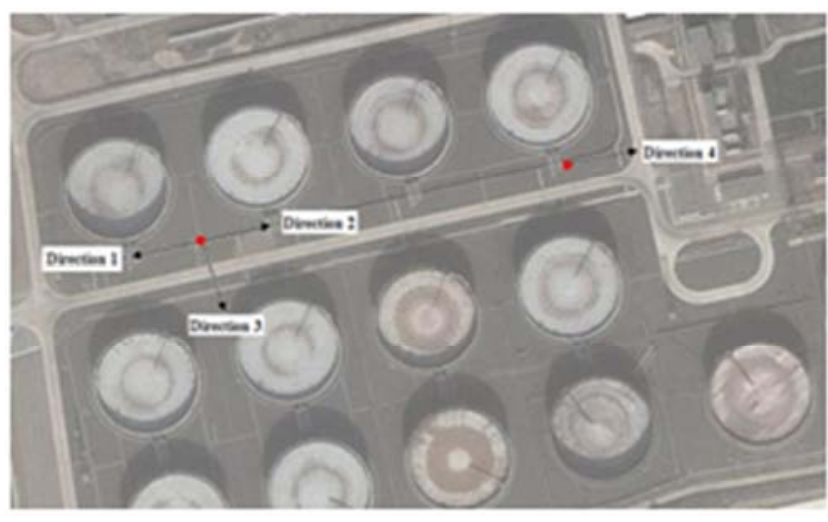

Figure 9. Potential gradient test direction.

\subsection{Table}

The tables should be clear and editable. All tables should be numbered by Arabic numbers like Table 1, Table 2, etc. There should be annotations above each table as following:

Table 1. Current output value of potentiostatic instruments.

\begin{tabular}{lllll}
\hline Potentiometer number & No. 1 & No. 2 & No.3 & Total \\
\hline Output current (A) & 5.2 & 3.3 & 8.5 & 17.0 \\
\hline
\end{tabular}

Table 2. Protect current calculation of regional CP system.

\begin{tabular}{llll}
\hline Protected objects & Protect area $\left(\mathbf{m}^{2}\right)$ & Protection current density $\left(\mathbf{m A} / \mathbf{m}^{2}\right)$ & Protection current $(\mathbf{A})$ \\
\hline epoxy coal asphalt anticorrosive layer of buried pipelines & 7316 & 3.5 & 25.61 \\
asphalt anticorrosive glass cloth of buried pipelines & 14245 & 2.5 & 35.61 \\
grounding & 116 & 60 & 6.96 \\
Total & & & 68.18 \\
\hline
\end{tabular}

Table 3. Potential gradient test results.

\begin{tabular}{lll}
\hline Test direction & DC potential $(\mathbf{m V})$ & DCpotential gradient $(\mathbf{m V} / \mathbf{m})$ \\
\hline Direction 1 & 160 & 16.0 \\
Direction 2 & 130 & 13.0 \\
Direction 3 & 98 & 9.8 \\
Direction 4 & 31 & 3.1 \\
\hline
\end{tabular}

\section{Conclusion}

In this paper, current requirement test has been conducted in a large oil field station. Three sets of shallow buried bedanalog cathodic protection systems have been established according to the separation of area. The minimum current density value were required for the effective cathodic protection and the potential distribution in every area were determined. All these results would benefit the future design of regional cathodic protection system. 


\section{Acknowledgements}

This paper is one of the achievements of the project of cathodic protection system for Wang Jiagou reservoir area, a key project of CNPC.

\section{References}

[1] Tang Zhao-lin, Zhang Xue-you, LIU gang. Simulated Feeding Test of Impressed Current Catholic Protection for a Natural Gas Pipelin [J]. Corrosion \& Protection, 2013, 34 (2): 161-163.

[2] Wang Jiang-feng, Li Hong-qi. Gas pipeline cathodic protection problem and managemen $\mathrm{t}[\mathrm{J}]$. Corrosion \& Protection, 2014 (7): 758-760.

[3] Ge Ai-tian, TU Ming-yue. Practice of Regional Cathodic Protection in Shaanjing Pipeline [J]. Corrosion \& Protection, 2009 (5): 343-345.

[4] Han Fei. Application of Current Requirement Test to Mitigation of DC Transit Stray Current Interference [J]. Corrosion \& Protection, 2015 (11): 1101-1103, 1108.

[5] Wu Guang-chun, Du Yan-xia, Lu Min-xu, Jiang Zi-tao, Tang
De-zhi. Status in Research on Effect of Grounding System on Regional Cathodic Protection and Solution [J]. Co, rrosion \& Protection, 2014 (11): 1065-1068, 1097.

[6] Long Tian-hui, Niu Shuang-hui. Determination of Protective Current Density of Pipeline in a Thermal Plant [J]. Corrosion \& Protection, 2012 (12): 1121-1122.

[7] Wang Zai-feng, Song Ji-wen, Chen Sheng-li, Sun Hu-yuan. Finite Element Simulation of Cathodic Protection Field and Potential Scanning System [J]. Total Corrosion Control, 2015 (12): 23-27.

[8] Zhang Ming-di, Li Hong-xi, Gao Hong-lei, Wan Fang-lin. Determination of cathodic protection current density for buried old pipelines [J]. Corrosion science and protection technology, 1996 (03).

[9] Yang Yong, He Jun, Li Ya-jun, Liu Jian. Selection of Electric Current Intensity for Cathodic Protection of Buried Steel Pipelines [J]. Corrosion \& Protection in Petrochemical Industry, 200926 (5).

[10] Shen Guang-ji, Gu Ying-cui, Xue Zhi-yuan, Zhao Jun, Su Lei. Discussion on Test Methods of Cathodic Protection Current Densit [J]. Total Corrosion Control, 2012:26 (6). 